\title{
FAKTOR-FAKTOR KESEHATAN KERJA TERHADAP PENINGKATAN PERSONAL HYGIENE PADA PETUGAS PENGANGKUT SAMPAH DI KOTA GORONTALO
}

\author{
${ }^{1}$ Hartati Inaku, ${ }^{2}$ Moh. Malik A. Hanafi
}

\begin{abstract}
Program Studi Budidaya Perairan Fakultas IImu-IImu Pertanian Universitas Muhammadiyah Gorontalo Jl. Prof. Dr. Mansoer Pateda, Pentadio Timur, Gorontalo, Indonesia 96212

Email: inakuhartati@gmail.com
\end{abstract}

\begin{abstract}
The purpose of this study was to determine the Factors Affecting Occupational Health in Improving Personal Hygiene in Garbage Transport Officers in the City of Gorontalo. The research design uses Analytic Survey with Cross Sectional approach. Sampling using Accidental Sampling technique with a sample of 50 respondents. Analysis of the study used a chi square test with a significant $\alpha=0.05$, the results obtained $p$ value $=0.001$ $(<0.05)$ which means there is an influence of knowledge with occupational health in improving personal hygiene, then the value of $p$ value $=0.416(<0,05)$ which means there is no influence of work period with occupational health in improving personal hygiene and the value of $p$ value $=0,000(<0.05)$ which means there is an influence of the use of personal protective equipment (PPE) with occupational health in improving personal hygiene in the garbage transport officer in Gorontalo City.
\end{abstract}

Keywords: Personal Hygiene, Occupational Health.

\section{Abstrak}

Tujuan penelitian ini adalah untuk mengetahui Faktor-faktor yang Mempengaruhi Kesehatan Kerja Dalam Peningkatan Personal Hygiene Pada Petugas Pengangkut Sampah di Wilayah Kota Gorontalo. Desain penelitian menggunakan Survey Analitik dengan pendekatan Cross Sectional. Pengambilan sampel menggunakan tekhnik Accidental Sampling dengan sampel 50 responden. Analisis penelitian menggunakan uji chi square dengan signifikan $\alpha=0,05$, hasil didapatkan $p$ value $=0,001 \quad(<0,05)$ yang berarti terdapat pengaruh pengetahuan dengan kesehatan kerja dalam peningkatan personal hygiene, kemudian didapatkan nilai $p$ value $=0,416(<0,05)$ yang berarti tidak terdapat pengaruh masa kerja dengan kesehatan kerja dalam peningkatan personal hygiene dan nilai $p$ value $=0,000(<0,05)$ yang berarti terdapat pengaruh pemakaian alat pelindung diri (APD) dengan kesehatan kerja dalam 
peningkatan personal hygiene pada petugas pengangkut sampah di Kota Gorontalo

Kata Kunci : Personal Hygiene, Kesehatan Kerja.

\section{PENDAHULUAN}

Di Indonesia, masalah kesehatan dan keselamatan kerja juga mengalami peningkatan yang signifikan yang dapat meningkatkan angka kesakitan maupun kematian. Diketahui kasus kejadian kecelakaan ditempat kerja pada tahun 2013 adalah yang paling tertinggi sebanyak 35.915 orang dan Aceh merupakan salah satu provinsi dengan angka kecelakaan kerja tertinggi pada tahun 2013 (Kementrian Kesehatan RI, 2015).

Profil Kesehatan Provinsi Gorontalo (2017), menyebutkan bahwa petugas pengangkut sampah setiap tahun jumlahnya terus bertambah. Petugas pengangkut sampah tercatat pada tahun 2016 sebanyak 295 jiwa, tahun 2017 dan 2018 sebanyak 300 jiwa. Meskipun tidak terdapat data mengenai kecelakaan atau penyakit akibat kerja pada pengangkut sampah di Provinsi Gorontalo, namun risiko adanya gangguan kesehatan karena paparan berbagai jenis sampah maupun kecelakaan kerja seperti luka ataupun tertimbun oleh sampah sangat mungkin terjadi.

Berdasarkan hasil studi pendahuluan di lapangan, diketahui gambaran tentang kehidupan dan kondisi lingkungan tempat petugas bekerja. Tempat dimana petugas bekerja di beberapa titik lokasi menjadi satu bagian dengan tempat pemukiman dimana petugas tersebut juga tinggal serta bersama keluarganya. Lingkungan yang kotor dan kontak langsung dengan sampah menjadi salah satu faktor risiko terjadi penularan penyakit. Dari 5 pekerja yang dimintai keterangan terdapat 2 pekerja yang mengatakan sering merasakan gatal-gatal di daerah tangan dan kaki setelah bekerja. Mereka beranggapan gatal-gatal tersebut terjadi karena adanya kontak langsung tanpa menggunakan pelindung diri dengan berbagai jenis sampah yang menyebabkan iritasi pada kulit. Para pekerja menganggap hal tersebut wajar dan sudah biasa sehingga mereka tidak merasa perlu memeriksakannya ke Puskesmas maupun di tempat pelayanan kesehatan lainnya. Dari keterangan petugas, didapatkan pula fakta bahwa terdapat beberapa kejadian akibat kecelakaan di tempat kerja antara lain: luka akibat tertabrak mobil, terkena serpihan beling kaca, terkena tusuk sate, dan terkena paku hingga akhirnya tetanus dan adanya korban yang meninggal di tahun 2018 kemarin. 
Dari hasil wawancara dengan koordinator petugas pengangkut sampah, diketahui terdapat kurang lebih 300 orang yang bekerja sebagai petugas pengangkut sampah pada tahun 2018-2019 yang tersebar di seluruh Wilayah Kota Gorontalo. Hasil observasi peneliti didapatkan petugas pengangkut sampah kurang memperhatikan kebersihan dirinya (personal hygiene) dan penggunaan alat pelindung diri (APD) saat bekerja. Selama pengumpulan sampah berlangsung, terdapat beberapa petugas yang tidak menggunakan APD sesuai standar, seperti dalam pemakaian sepatu dengan jenis berbeda yaitu ada yang memakai sepatu jenis kain dan sebagian menggunakan sepatu boot. Ditemukan juga petugas yang tidak menggunakan penutup kepala dan sarung tangan dan bahkan terdapat petugas yang memakai sarung tangan kain dengan kondisi yang sudah tidak layak dipakai seperti kotor dan sudah bolong.

Beberapa teori dan penelitian mengenai faktor-faktor yang berhubungan dengan kejadian masalah kesehatan dan keselamatan kerja pada petugas pengangkut sampah diketahui disebabkan oleh beberapa faktor di antaranya adalah usia, pengetahuan, masa kerja yang cukup lama, penggunaan alat pelindung diri (APD) yang tidak sesuai standar serta tidak memperhatikan personal hygiene. Semakin sering ini terjadi, besar kemungkinan dapat mempengaruhi kesehatan para pekerja pengangkut sampah (Jambi, et. al., 2017).

\section{METODE PENELITIAN}

Desain penelitian yang digunakan adalah desain survey analitik dengan menggunakan pendekatan cross sectional, yaitu suatu penelitian untuk mempelajari hubungan antara faktor resiko (independen) dengan faktor efek (dependen), dimana melakukan observasi atau pengukuran variabel sekali dan sekaligus pada waktu yang sama (Notoatmodjo, 2012).

Variabel bebas dalam penelitian ini adalah usia, status pendidikan, tingkat pengetahuan, masa kerja dan penggunaan alat pelindung diri (APD) sedangkan variabel terikat dalam penelitian ini adalah Personal Hygiene Petugas Pengangkut Sampah.

Definisi operasional adalah mendefinisikan variabel secara operasional berdasarkan karakteristik yang diamati, sehingga memungkinkan peneliti untuk melakukan observasi atau pengukuran secara cermat terhadap suatu objek atau fenomena (Budiman, 2011). 
Tabel 3.1. Definisi Operasional

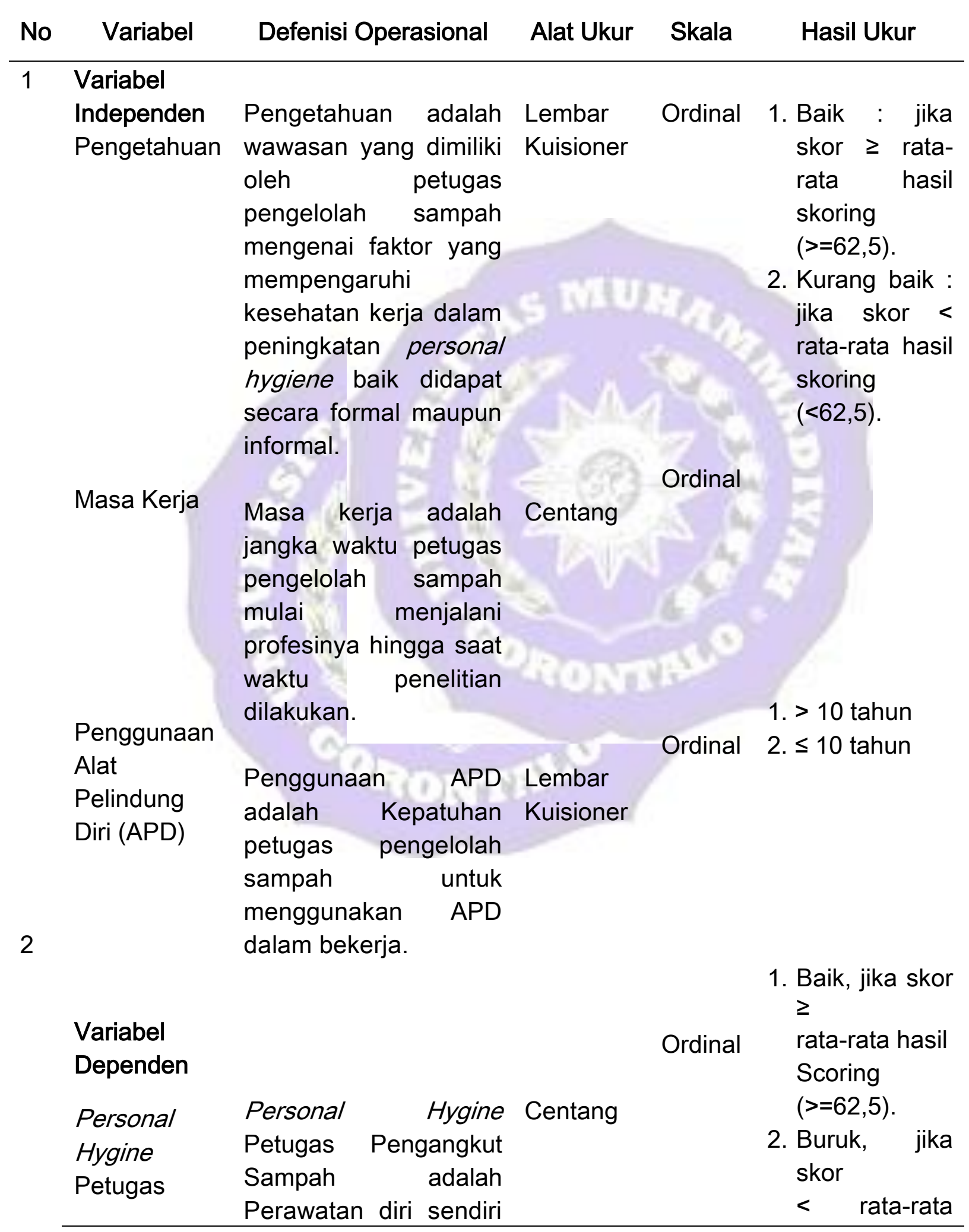




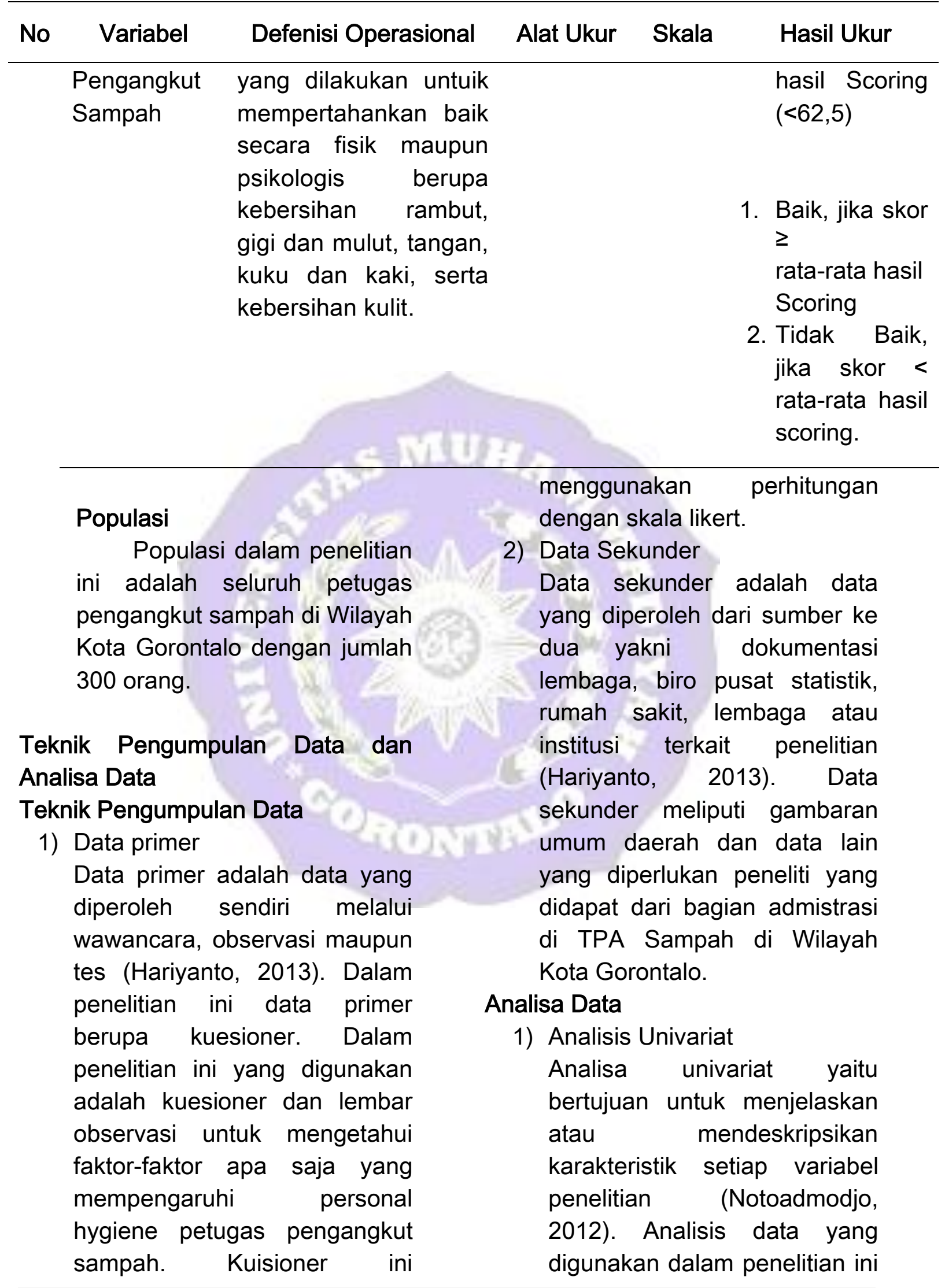


bertujuan untuk menjelaskan atau mendeskripsikan karakteristik setiap variabel penelitian. Karakteristik responden dalam hal ini adalah petugas pengelolah sampah.

2) Analisis Bivariat

Analisa bivariat merupakan analisa hasil dari variabel independen yang diduga mempunyai hubungan dengan variabel

dependen (Notoadmodjo, 2012). Analisis bivariat digunakan untuk melihat kemungkinan hubungan antara variabel independen dan dependen dengan menggunakan analisis uji chi square. Melalui uji statistic chi square akan diperoleh nilai $p$, dimana dalam penelitian ini digunakan tingkat kemanaknaan sebesar 0,005 .

\section{a. Metode Pengolahan Data}

Metode pengalihan dijabarkan sebagai berikut:

1. Editing merupakan upaya untuk memeriksa kembali kebenaran data yang diperoleh atau dikumpulkan. Editing dapat dilakukan pada tahap pengumpulan data atau setelah data terkumpul.

2. Coding merupakan kegiatan pemberian kode interval, terhadap data yang terdiri atas beberapa kategori.

3. Tabulasi merupakan penyusunan data yang diperoleh berdasarkan variabel yang akan diteliti dengan cara tabulasi.

4. Entri data merupakan kegiatan memasukan data yang telah dikumpulkan kedalam master tabel atau database komputer, kemudian membuat distribusi frekuensi sederhana atau bisa juga dengan membuat tabel kontigensi.

\section{HASIL DAN PEMBAHASAN}

Berdasarkan hasil penelitian yang dilakukan, diperoleh distribusi responden berdasarkan jenis kelamin pada Tabel 1.

Tabel 1 Distribusi Responden berdasarkan Jenis Kelamin

Prese Jenis Kelamin Frekuensi(n) ntase

\begin{tabular}{lcc} 
& & $(\%)$ \\
\hline Laki-laki & 50 & 100 \\
Perempuan & 0 & 0 \\
Total & 50 & 100 \\
\hline
\end{tabular}

Sumber : Data Primer, 2019

Berdasarkan Tabel 1 menunjukkan bahwa semua responden berjenis kelamin laki-laki yaitu berjumlah 50 responden (100\%). 
Distribusi Responden berdasarkan Usia

Berdasarkan hasil penelitian yang dilakukan, diperoleh distribusi responden berdasarkan usia pada Tabel 2. Berdasarkan Tabel 2 diketahui bahwa usia 26-35 Tahun yang paling banyak bekerja di TPA yaitu berjumlah 18 responden (36\%), sedangkan usia 56-65 tahun paling sedikit berjumlah 1 responden (2\%), dan sisanya usia 17-25 tahun yang berjumlah 10 responden (20\%), usia $36-45$ tahun berjumlah 13 responden ( $26 \% 0$ dan usia $46-55$ tahun berjumlah 8 responden $(16 \%)$.

\begin{tabular}{ccc} 
Tabel 2 & \multicolumn{2}{c}{$\begin{array}{c}\text { Distribusi } \\
\text { berdasarkan Usia }\end{array}$} \\
\hline $\begin{array}{c}\text { Usia } \\
\text { (Tahun) }\end{array}$ & $\begin{array}{c}\text { Frekuens } \\
\text { i(n) }\end{array}$ & $\begin{array}{c}\text { Persentas } \\
\mathbf{e}(\%)\end{array}$ \\
\hline $17-25$ & 10 & 20 \\
$26-35$ & 18 & 36 \\
$36-45$ & 13 & 26 \\
$46-55$ & 8 & 16 \\
$56-65$ & 1 & 2 \\
\hline Total & $\mathbf{5 0}$ & 100 \\
\hline
\end{tabular}

Sumber : Data Primer, 2019

Distribusi Responden berdasarkan Pendidikan

Berdasarkan hasil penelitian yang dilakukan, diperoleh distribusi responden berdasarkan pendidikan pada Tabel 3 yang menunjukkan bahwa sebagian besar responden yang bekerja di TPA memiliki pendidikan dengan kategori SD/sederajat berjumlah 23 responden (46\%), sedangkan paling sedikit terdapat 1 responden (2\%) yang tidak duduk dibangku sekolah dan sisanya SMP/sederajat berjumlah 18 responden (36\%) dan SMA/sederajat berjumlah 8 responden (16\%).

$\begin{array}{cl}\text { Tabel } 3 & \begin{array}{l}\text { Distribusi Responden } \\ \text { berdasarkan } \\ \text { Pendidikan }\end{array}\end{array}$

\begin{tabular}{ccc}
\hline $\begin{array}{c}\text { Pendidikan } \\
\text { Tertinggi }\end{array}$ & $\begin{array}{c}\text { Frekuens } \\
\mathbf{i}(\mathbf{n})\end{array}$ & $\begin{array}{c}\text { Persentas } \\
\mathbf{e}(\%)\end{array}$ \\
\hline Tidak Sekolah & 1 & 2 \\
SD/Sederajat & 23 & 46 \\
SMP/Sederajat & 18 & 36 \\
SMA/Sederajat & 8 & 16 \\
\hline Total & $\mathbf{5 0}$ & $\mathbf{1 0 0}$ \\
\hline
\end{tabular}

Sumber : Data Primer, 2019

\section{Distribusi Responden berdasarkan Pengetahuan}

Berdasarkan hasil penelitian yang dilakukan, diperoleh distribusi responden berdasarkan pengetahuan pada Tabel 4, yang menyatakan bahwa pengetahuan responden dengan kategori kurang baik yang paling banyak bekerja di TPA yaitu berjumlah 29 responden $(58 \%)$, sedangkan pengetahuan dengan kategori baik paling sedikit berjumlah 21 responden (42\%). 


\begin{tabular}{ccc}
\hline Tabel 4 & $\begin{array}{c}\text { Distribusi } \\
\text { berdasarkan } \\
\text { Pengetahuan }\end{array}$ \\
\hline Pengetahuan & $\begin{array}{c}\text { Frekuens } \\
\text { i(n) }\end{array}$ & $\begin{array}{c}\text { Pres } \\
\text { entas } \\
\text { e (\%) }\end{array}$ \\
\hline Baik & 21 & 42 \\
Kurang Baik & 29 & 58 \\
Total & 50 & 100 \\
\hline
\end{tabular}

Sumber : Data Primer, 2019

Distribusi Responden berdasarkan Masa Kerja

Berdasarkan hasil penelitian yang dilakukan, diperoleh distribusi responden berdasarkan masa kerja pada Tabel 5 yang menunjukkan bahwa responden dengan masa kerja $\leq 10$ tahun yang paling banyak bekerja di TPA yaitu berjumlah 38 responden $(76 \%)$, sedangkan responden dengan masa kerja $>10$ tahun paling sedikit berjumlah 12 responden (24\%).

Tabel 5 Distribusi Responden berdasarkan Masa Kerja

\begin{tabular}{ccc}
$\begin{array}{c}\text { Masa Kerja } \\
\text { (Tahun) }\end{array}$ & $\begin{array}{c}\text { Frekuens } \\
\mathrm{i}(\mathrm{n})\end{array}$ & $\begin{array}{c}\text { Persentase } \\
(\%)\end{array}$ \\
\hline$\leq 10$ & 38 & 76 \\
$>10$ & 12 & 24 \\
Total & 50 & 100 \\
\hline
\end{tabular}

Sumber : Data Primer, 2019
Distribusi Responden berdasarkan Alat Pelindung Diri (APD)

Berdasarkan hasil penelitian yang dilakukan, diperoleh distribusi responden berdasarkan APD pada Tabel 6 menyatakan bahwa responden dengan APD buruk adalah yang paling banyak ditemukan di TPA yaitu berjumlah 39 responden (78\%), sedangkan responden dengan APD baik paling sedikit berjumlah 11 responden (22\%).

Tabel 6 Distribusi Responden berdasarkan APD

\begin{tabular}{ccc}
\hline APD & $\begin{array}{c}\text { Frekuens } \\
\mathrm{i}(\mathrm{n})\end{array}$ & $\begin{array}{c}\text { Presentase } \\
(\%)\end{array}$ \\
\hline Buruk & 39 & 78 \\
Baik & 11 & 22 \\
\hline Total & 50 & 100
\end{tabular}

Sumber : Data Primer, 2019

Analisis Bivariat

Analisa bivariat dalam penelitian ini adalah faktor-faktor yang mempengaruhi kesehatan kerja dalam peningkatan personal hygiene pada petugas pengangkut sampah di Wilayah Kota Gorontalo. Hal ini dapat lihat pada Tabel 7 Berdasarkan tabel 4.7 diatas, diketahui bahwa sebagian besar responden memiliki pengetahuan dengan kategori kurang yaitu 28 responden dan hanya 9 responden masuk kategori baik. Sementara 
untuk masa kerja, responden yang memiliki pengalaman kerja dengan kategori $>10$ tahun hanya 1 responden, sebagaian besar responden berada dalam kategori memiliki masa kerja $\leq 10$ tahun. Dan pada pemakaian alat pelindung diri, responden yang berada dalam kategori baik sebanyak 10 responden dan hampir seluruhnya atau 39 responden ada dalam kategori buruk.

Tabel 4.7 Distribusi faktor-faktor yang mempengaruhi kesehatan kerja dalam peningk personal hygiene pada petugas pengangkut sampah di Wilayah Kota Gorontalo

\begin{tabular}{lcllll}
\hline & Faktor-faktor yang & Personal Hygiene & & \\
No & Mempengaruhi Five Moment & (\%) & $\rho$
\end{tabular} \begin{tabular}{ccccccc} 
& Hand Hygiene & Kurang & Baik & & & \\
\cline { 3 - 6 } & & & & & & \\
\hline 1 & Pengetahuan: & 28 & 1 & 29 & $58 \%$ & 0.001
\end{tabular}

\begin{tabular}{lcccccc}
\hline & Total & & & $\mathbf{5 0}$ & $\mathbf{1 0 0}$ & \\
\hline \multirow{2}{*}{2} & Masa Kerja: & 29 & 9 & 38 & $76 \%$ & 0.416 \\
& $\leq 10$ tahun & 11 & 1 & 12 & $24 \%$ &
\end{tabular}

\begin{tabular}{ccccccc}
\hline & Total & & & 50 & 100 & \\
\hline 3 & Pemakaian Alat Pelindung Diri: & 39 & 0 & 39 & $78 \%$ & 0.000 \\
Buruk & Baik & 1 & 10 & 11 & $42 \%$ &
\end{tabular}

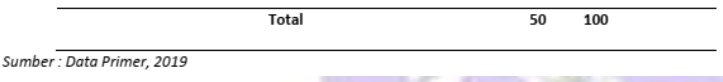

Berdasarkan uji statistik dengan menggunakan chi square menunjukkan nilai pengetahuan $p$ value $=0,001 \quad(<0,05)$ maka dapat disimpulkan adanya pengaruh yang bermakna/signifikan antara pengetahuan dengan kesehatan kerja dalam peningkatan personal hygiene pada petugas pengangkut sampah. Sementara nilai pemakaian alat pelindung diri (APD) didapatkan $p$ value $=0,000(<0,05)$ maka dapat disimpulkan adanya pengaruh yang bermakna/signifikan antara pemakaian alat pelindung diri (APD) dengan kesehatan kerja dalam peningkatan personal hygiene pada petugas pengangkut sampah. Dan nilai masa kerja yaitu $p$ value $=.416$ $(<0,05)$ yang artinya tidak ada pengaruh yang bermakna/signifikan antara masa kerja dengan kesehatan kerja dalam peningkatan personal hygiene pada petugas pengangkut sampah.

\section{Penutup}

Berdasarkan hasil penelitian dan pengujian, maka dapat disimpulkan bahwa

1. ada pengaruh yang bermakna/signifikan antara pengetahuan dengan kesehatan kerja dalam peningkatan personal hygiene - pada petugas pengangkut sampah di Kota Gorontalo.

2. Dari hasil analisis bivariat menunjukkan bahwa tidak terdapat hubungan yang signifikan antara masa kerja dengan personal higiene.

3. Adanya pengaruh yang bermakna/signifikan antara pemakaian alat pelindung diri (APD) dengan kesehatan kerja dalam peningkatan personal hygiene pada petugas pengelolah sampah di Kota Gorontalo.

4. Berdasarkan uji statistik terdapat pengaruh faktor tingkat pengetahuan dan pemakaian alat pelindung diri (APD), sementara faktor masa kerja tidak ada pengaruhnya terhadap 


\section{Gurnal Ilmiah Media Publikasi Ilmu Pengetahuan dan Teknologi}

peningkatan personal hygiene
pada petugas pengangkut
sampah di Wilayah Kota
Gorontalo.

\section{DAFTAR PUSTAKA}

Abbas, Sudaeri. 2013. Gambaran Penyakit Kulit Pada Petani Tambak di Desa Salipolo Kecamatan Cempa Kabupaten Pinrang.

Penelitian. Makassar: Universitas Muslim Indonesia. Diakses 29 November 2018. Adzim, Hebbie Ilma. 2013. Pengertian dan Elemen Sistem Manajemen K3 (Keselamatan dan Kesehatan Kerja). Ahli K3 Umum. (https://sistemmanajemenkes elamatankerja.blogspot.co.id/ 2013/09/tujuan-k3keselamatan-dankesehatan.html?m=1).

Diakses 29 November 2018.

Aisyah, Faddilatul. 2012. Hubungan Hygiene Perorangan dan Pemakaian Alat Pelindung Diri dengan Keluhan Gangguan Kulit Pada Pekerja Pengupas Udang di Kelurahan Pekan Labuhan Kecamatan Medan Labuhan.
Departemen

Kesehatan

Lingkungan. Universitas Sumatra Utara. Diakses 29 November 2018.

Ambarsari, Dwi Desi., Mulasari, Surahma Asti. 2018. FaktorFaktor yang Berhubungan dengan Keluhan Subyektif Dermatitis Kontak Iritan pada Petugas Pengepul Sampah di Wilayah Kota Yogyakarta. Jurnal Kesehatan Lingkungan Indonesia, 17 (2), 2018, 80 86. Diakses 29 November 2018.

Ambarwati, E.R. \& Sunarsih, T. 2011. KDPK Kebidanan : Teori dan Apilkasi.

Yogyakarta: Nuha Medika.

Anizar. 2010. Teknik Keselamatan dan Kesehatan Kerja di Industri. Yogyakarta: Graha IImu.

Ardiyanti, Septiana., Hartini, Eko. 2015. Faktor Risiko Terjadinya Penyakit Akibat Kerja Pada Petugas Pengangkut Sampah di Kecamatan Semarang UtaraKota Semarang. Diakses pada tanggl 18 Juli 2019. Arrazy, Syafran., Sunarsih, Elvi., dan Rahmawati, Anita. 2014. 
Penerapan Sistem

Manajemen Keselamatan

Kebakaran di rumah Sakit

DR. Sobirin Kabupaten Musi

Rawas. Diakses 29

November 2018.

Astriyanti T, Lerik MDC, Sahdan M.

2010. Perilaku hygiene

perorangan pada narapidana

penderita penyakit kulit dan

bukan penderita penyakit kulit

di lembaga pemasyarakatan

klas // A Kupang Tahun 2010.

Jurnal MKM 2010; 5(1): 33-

40. Diakses 29 Juni 2019.

Azizah I, Setyowati W. 2011.

Hubungan tingkat

pengetahuan ibu pemulung tentang personal hygiene dengan kejadian skabies pada balita di tempat pembuangan akhir Kota Semarang. Jurnal Dinamika Kebidanan 2011; 1(1): 71-81. Diakses 29 Juni 2019.

Badraningsih L, Enny Zuhny. 2013. Kecelakaan Akibat Kerja
(KAK) dan Penyakit Akibat

Kerja (PAK). (http//:

www.staff.uny.ac.id-sites-

filespendidikan). Diakses 29

November 2018.

Bakti, Zainal. 2014. Sistem Manajemen Keselamatan dan Kesehatan Kerja (SMK3) Sesuai PP No.50 Tahun 2012. (http://www.a2k4ina.net/informasi/163-sistemmanajemen-keselamatandan-kesehatan-kerja-smk3sesuai-pp-no-50-tahun2012.html). Diakses 29 November 2018.

Budiman. 2013.2 Penelitian Kesehatan. Buku pertama. Bandung: PT Refika Aditama. Budiono dan Cahyawati. 2011. Faktor yang Berhubungan dengan Kejadian Dermatitis pada Nelayan. (Jurnal). Kesmas Vol.6 hal 134-141. Diakses 29 November 2018. Chandra, Budiman. 2009. IImu Kedokteran 